\title{
INVESTIGACIÓN
}

Recibido: 27/03/2018 --- Aceptado: 18/05/2018 --- Publicado: 15/09/2018

\section{EL HUMOR EN LA COMUNICACIÓN POLÍTICA: LA CONSTITUCIÓN ESPAÑOLA EN LA COLUMNA "ESCENAS POLÍTICAS" DE CAMPMANY}

\section{The humor in political communication: the Spanish Constitution in the column "political scenes" of Campmany}

Aurora García González1: Universidad de Vigo. España

auroragg@uvigo.es

Sarai Lagos Area: Universidad de Vigo. España

sarailagos@gmail.com

Ma Lourdes Román Portas: Universidad de Vigo. España

romanportas@gmail.com

\section{RESUMEN}

El trabajo estudia los artículos publicados en la columna "Escenas políticas", durante los tres meses que concluyeron en la ratificación de la democracia en España por medio de la nueva Constitución. El humor desde el columnismo de Jaime Campmany permite advertir el ámbito de libertad en el que consiguió escribir Este trabajo plantea el estudio de un tipo de periodismo que se abrió paso en los difíciles años de la transición política y que permitió introducir determinados temas desde el prisma del humor. Los estudios de comunicación sobre el humor ilustran el complejo papel que juega en la formación de percepciones. La habilidad para usar y reconocer el humor no es trivial, sino que puede explicar el éxito en un grupo o en diferentes contextos sociales. Los años transcurridos entre la muerte de Franco y el advenimiento del socialismo en España estuvieron jalonados por la aprobación de la Ley de Reforma Política, la Constitución de 1978 y sucesivos procesos electorales. Con una metodología de análisis descriptivo ha sido posible establecer que Campmany abordó en su columna política los asuntos públicos de la nación, en concreto la aprobación del texto constitucional, desde una posición conservadora y con un gran sentido del humor.

\section{PALABRAS CLAVE}

Comunicación política; Humor; Opinión Pública; análisis descriptivo; Periodismo político; Constitución; Transición española

\footnotetext{
${ }^{1}$ Universidad de Vigo. España auroragg@uvigo.es
} 


\begin{abstract}
The work studies the articles published in the column "Political scenes", during the three months that ended in the ratification of democracy in Spain through the new Constitution. The humor from the columnism of Jaime Campmany allows to notice the scope of freedom in which he managed to write. This work proposes the study of a type of journalism that made its way in the difficult years of the political transition and that allowed to introduce certain topics from the prism of humor. Communication studies on humor illustrate the complex role that it plays in the formation of perceptions. The ability to use and recognize humor is not trivial, but it can explain the success in a group or in different social contexts. The years between the death of Franco and the advent of socialism in Spain were marked by the approval of the Law of Political Reform, the Constitution of 1978 and successive electoral processes. With a methodology of descriptive analysis, it has been possible to establish that Campmany addressed in his political column the public affairs of the nation, specifically the approval of the constitutional text, from a conservative position and with a great sense of humor.
\end{abstract}

\title{
KEY WORDS
}

Politic Communication; Humour; Public Opinion; Descriptive Analysis; Political Journalism; Constitution; Spanish Transition

\section{O HUMOR NA COMUNICAÇÃO POLÍTICA: A CONSTITUIÇÃO ESPANHOLANA COLUNA “CENAS POLÍTICAS” DE CAMPMANY}

\section{RESUME}

O trabalho estuda os artigos publicados na coluna Cenas Políticas, durante os três meses que concluíram na ratificação da democracia na Espanha por meio da nova Constituição. O humor desde o colunismo de Jaime Campmany permite advertir o âmbito de liberdade no qual conseguiu escrever. Este trabalho planeja o estudo de um tipo de jornalismo que abriu passo nos difíceis anos da transição política e que permitiu introduzir determinados temas desde o prisma do humor. Os estudos de comunicação sobre o humor ilustram o complexo papel que joga na formação de percepções. A habilidade para usar e reconhecer o humor não é trivial, senão que pode explicar o êxito em um grupo ou em diferentes contextos sociais. Os anos transcorridos entre a morte de Franco e a chegada do socialismo na Espanha estiveram marcados pela aprovação da Lei de Reforma Política de 1978 e sucessivos processos eleitorais. Com uma metodologia de analises descritiva foi possível estabelecer que Campmany abordou em sua coluna política os assuntos públicos da nação, em concreto a aprovação do texto constitucional, desde uma posição conservadora e com grande sentido de humor.

\section{PALAVRAS CHAVE}

Comunicação política; Humor; Opinião Pública; Analises descritivo; Jornalismo político; Constituição; Transição espanhola 


\section{Como citar el artículo}

García González, A., Lagos Area, S., Román Portas, Mª L. (2018). El humor en la comunicación política: la Constitución Española en la columna "escenas políticas" de Campmany [The humor in political communication: the Spanish Constitution in the column "political scenes" of Campmany] Vivat Academia. Revista de Comunicación, $\mathrm{n}^{\mathrm{o}}$ 144, 51-67. doi: http://doi.org/10.15178/va.2018.144.51-67. Recuperado de http:/ / www.vivatacademia.net/index.php/vivat/article/view/1082

\section{INTRODUCCIÓN}

Este trabajo plantea el estudio de un tipo de periodismo que se abrió paso en los difíciles años de la transición política y que permitió introducir determinados temas desde el prisma del humor. Los estudios de comunicación sobre el humor ilustran el complejo papel que juega en la formación de percepciones. La habilidad para usar y reconocer el humor no es trivial sino que puede explicar el éxito en un grupo o en diferentes contextos sociales. Existe ya una tesis que profundiza sobre el humor en el periodismo de opinión desde la columna "Escenas políticas" del diario $A B C$ (Morales Castillo, 1999). En ella se analizaron los recursos del humor y su eficacia, los distintos aspectos de lo cómico, los procedimientos caricaturescos y las reducciones satírico-burlescas. Ese espléndido estudio abrió la puerta a las observaciones de este trabajo. Se trata ahora de poner el acento en la vertiente comunicativa donde el humor se convierte en un prisma para la observación de la realidad y para suavizar la presentación de los asuntos complejos.

Algunos autores (Lynch, 2002, p. 423-445) señalan que la investigación en comunicación solamente ha rozado la superficie del mundo del humor aunque, indudablemente el humor y la risa son partes esenciales de lo humano. La investigación, tanto en comunicación como en sociología, se ha ocupado de cómo funciona el humor en un contexto social. La sociología ha atendido a funciones del humor como la identificación, la diferenciación, el control y la resistencia, mientras que la comunicación se ha ocupado más de cerca de los tipos específicos de humor que producen funciones comunicativas (tomar el pelo, quitar el aburrimiento, llamar la atención, persuadir...) en contextos sociales más pequeños.

El humor ayuda a reducir la tensión social y distraer de los problemas cotidianos que, como ha señalado Mendelsohn, evitan la quiebra de las sociedades (1966). Y hay autores que sostienen que la risa es un instrumento para oponerse al orden establecido. "Y en la forma de las caricaturas políticas, se encuentra un medio constante de respuesta y opinión a los asuntos públicos que las figuras políticas manejan. En períodos electorales, esto se magnifica" (Batjin, 2002).

La tesis que dio origen a estas consideraciones, sostiene también que el humor es parte del periodismo de opinión, "pues a través de este recurso los periodistas representan la realidad de manera lúdica, aplicando sobre ella aspectos afectivos e intelectuales, que pretenden moldear la opinión de sus lectores". (Morales del Castillo, 1999, p. 19)

En cualquier caso la columna "Escenas políticas" que firmaba Jaime Campmany, 
analizada en 1978, en un concreto momento de nuestra evolución histórica, expresó con buen humor y con argumentos contundentes la opinión de una parte de los españoles ante el cambio político. Y sirvió para ampliar el margen de libertad de expresión al dejar escrito, más libres las plumas que las lenguas, lo que no era frecuente exponer en la prensa. El mismo autor admitía, "creo que logré decir muchas de las cosas que en aquel tiempo estaban prohibidas, gracias a usar un tono de humilde intimismo y hasta de reproche lírico que me proporcionaron un cierto éxito" (Campmany, 1997, p. 21).

A este respecto señala Cantavella que

Cuando, tras la muerte de Franco, los periodistas pudieron hacer uso de la libertad de expresión y se permitió el libre juego de los partidos políticos, Campmany optó por la crítica severa de las opciones contrarias. Pero tal vez se dio cuenta de que, si entraba por esta senda, los enfrentamientos iban a ser demasiado violentos. Optó entonces, de acuerdo con su carácter plácido y amistoso, por practicar la vía del humor, que permite ser igual de contundente en los razonamientos, pero dándole una apariencia de lenidad, porque suaviza los contornos y provoca la sonrisa (y hasta es posible llegar a la carcajada). Es más fácil prevenir el enfado de los demás cuando las cosas se dicen de manera jacarandosa (Cantavella, 2012, p.78).

\section{OBJETIVOS}

El trabajo desarrollado en páginas posteriores tenía como objetivos principales los siguientes:

- Poner el acento en la vertiente comunicativa en la que el humor se convierte en un prisma para la observación de la realidad y simplificación de asuntos complejos.

- Localizar Los artículos que abordaron la temática constitucional en un momento políticamente delicado de la historia de España y ver el papel que el humor desempeñó en los mismos.

- Comprobar el empleo del humor que hace este autor al presentar la comunicación política.

\section{METODOLOGÍA}

Para alcanzar los objetivos señalados, se optó por emplear una metodología de análisis descriptivo. El análisis descriptivo es una herramienta poderosa que ayuda a evidenciar los caminos mentales seguidos por los investigadores. El movimiento de pensamiento que refleja conforma un motor básico para revisar el estatuto de las propias construcciones teóricas a la hora de hacer ciencia.

En el presente trabajo, se ha querido recorrer la vía que nos permitiera ampliar los límites de las herramientas formales e incluir como necesarias las condiciones preliminares que el análisis descriptivo permite establecer, delimitando mejor los 
alcances de las construcciones científicas y verificando el conocimiento propuesto a partir de lo que podría denominarse una prueba metodológica estándar.

El sentido común, el saber compartido, la ciencia, la objetividad, no son más que modos de situarse en el mundo para tratar de entenderlo, pero sin olvidar que se hace desde un contexto particular, en una cultura dada y según los criterios de una comunidad científica, que dice qué se califica y acepta como tal para adquirir valor de prueba.

\section{DISCUSIÓN}

\subsection{El contexto histórico (en que se desarrolla nuestro análisis)}

Los años transcurridos entre la muerte de Franco y el advenimiento del socialismo en España estuvieron jalonados por la aprobación de la Ley de Reforma Política, la Constitución de 1978 y sucesivos procesos electorales.

La Ley de Asociaciones Políticas (aprobada el 9 de junio de 1976) fue ya reflejada en los días siguientes en varios chistes de Perich y otros humoristas españoles sobre la Reforma y el derecho de asociaciones. El 15 de diciembre de 1976 tuvo lugar el Referéndum para la Reforma. Los medios se hicieron eco de los resultados del mismo y de la importancia política de la Ley aprobada. $A B C$ titulaba su editorial "Un resultado que no deja lugar a dudas", y decía "El resultado del Referéndum ha confirmado en todos sus datos fundamentales, la previsión más razonable: abrumadora mayoría de votos afirmativos; exigua minoría de votos negativos y en blanco, y un porcentaje de abstenciones que no rebasa las estimaciones normales en estos casos". Fueron los primeros pasos hacia el nuevo orden que sancionaría una nueva Constitución.

Tras el Referéndum del 15 de diciembre España entró en una etapa que podría calificarse de constituyente con la celebración de las primeras elecciones de la democracia y la elaboración del nuevo texto constitucional. La extrema izquierda y la ETA flanquearon trágicamente todo el proceso de Reforma, con una actividad brutal, que a veces se juntaba con las no menos brutales aberraciones de la extrema derecha. El 9 de abril de 1977 se legalizó el Partido Comunista. En el mes siguiente Don Juan de Borbón cedía sus derechos dinásticos a su hijo Juan Carlos. Mientras, la situación social se deterioraba paulatinamente.

El 15 de junio de 1977 se celebraron elecciones generales. Las elecciones dieron el triunfo para la UCD. Los resultados se tradujeron en 165 escaños para UCD, 118 para el PSOE, 20 para el PCE, 16 para AP, 11 para CIU, 8 para PNV y 6 para el PSP. Es decir, una fuerte derecha nacional y un vigoroso PSOE en las regiones, como en los tiempos del reinado de Alfonso XIII.

El 6 de diciembre de 1978 la Constitución convirtió a España en monarquía parlamentaria basada en el sufragio universal. Y el sistema de partidos fue un acuerdo aceptado por la inmensa mayoría de los españoles. Además de asegurar las libertades democráticas, prometía una solución de los problemas regionales que tanto obsesionaban a los españoles del momento, con la explosión potencial de las autonomías. Puede decirse que el pueblo español votó por la moderación. Durante el período en que se trabajaba para la elaboración de esta Constitución, el Gobierno, obsesionado por la política había desatendido problemas económicos, que llevarían a 
España al borde del colapso.

\subsection{El contexto comunicativo, los cambios en la información}

En esta etapa la política española respecto a la información atravesó fases muy definidas. Entre noviembre de 1975 y junio de 1977 vivió una primera fase de adaptación. La prensa diaria seguía enfrentándose a una legislación obsoleta y al sistema de funcionamiento heredado del franquismo, agravado además por la crisis económica en su conjunto.

El primer gobierno de Suárez inició diversas transformaciones: el ministro de Información, Reguera Guajardo, publicó un Real Decreto sobre libertad de expresión y convirtió TVE en un organismo autónomo. La Constitución de 1978 supuso la desaparición de las cautelas políticas sobre la prensa y la entronización del principio de la libertad de expresión y del derecho de los ciudadanos a la información (Sinova, 1989, p. 272).

El artículo 20 de la Constitución establecía el derecho a la emisión y recepción de información veraz por cualquier medio de difusión, el derecho a la cláusula de conciencia y al secreto profesional, la prohibición de la censura previa y el control parlamentario de los medios de comunicación social dependientes del Estado. Esta regulación de la prensa estatal originó diversas polémicas acerca de la conveniencia del cierre de estos periódicos.

En los siguientes gobiernos de UCD desaparecería el Ministerio de Información y Turismo, sustituido por una Secretaría de Estado para la Información; se crearían las primeras televisiones autonómicas; se abrirían numerosas emisoras de FM; desaparecería la prensa estatal y las hojas del lunes y acabaría el monopolio informativo de Radio Nacional de España.

En febrero de 1978, 73 empresas periodísticas, editoras de los periódicos diarios no estatales constituyeron la Asociación de Editores de Diarios Españoles (AEDE), admitida en el mes de mayo del mismo año como miembro de pleno derecho de la Federación Internacional de Editores de Periódicos (FIEJ).

\subsection{Estudio de la columna “Escenas políticas" 1978: en torno a la Constitución}

Los primeros artículos que abordaron la temática constitucional se localizan en el mes de octubre en el que, aunque esporádicas, aparecen referencias al preocupante tema de la Constitución que se estaba gestando. La columna política de Campmany enfrentó los asuntos públicos de la nación, en concreto la aprobación del texto constitucional, desde una posición conservadora y con un gran sentido del humor.

\subsubsection{Preparando el terreno. Cinco artículos de octubre.}

La columna "Escenas Políticas" de Campmany aborda por primera vez el asunto de la Constitución en el mes de octubre de 1978, de manera tangencial, por alusiones comparativas a momentos similares, A mediados de octubre, con el título "Aquella tarde en Cebreros" establece el autor una comparación entre dos momentos constitucionales con el siguiente exordio: “Un día entre los días don Manuel Azaña 
pasó por Cebreros" (Campmany, 1978, p. 10) que era una manera amena y fácil de ubicar al lector, sabedor como todos los españoles de que este pueblo era cuna del entonces presidente del Gobierno, Adolfo Suárez.

La columna introduce una primera alusión, no exenta de ironía, a la situación: “El texto constitucional está ya en la última mesa de las discusiones y de ahí ha de salir para pasar por el cristal de las urnas soberanas" (Campmany, 1978, p. 10). En esta ocasión el argumento que utiliza es favorable, con clara referencia al problema del nacionalismo periférico que continuaba sin resolverse:

Porque podrá decirse que la Constitución está escrita, en algunos puntos, con renglones torcidos, pero su texto va encaminado limpiamente hacia una hermosa empresa de libertad. Ni un solo país de España puede quedar fuera de esa seguridad jurídica que la Constitución ofrece a la libertad y la igualdad de todos los españoles. (Campmany, 1978, p. 10)

Y la retórica del autor redondea el argumento con los elementos de la peroratio clásica: “Aquel niño del pueblecito de Ávila tendrá que irse al Parlamento de la monarquía parlamentaria y explicarnos cómo va a atar las manos a los que quieren seguir matando los toros a pedradas en el ruedo ibérico, como aquella tarde en Cebreros" (Campmany, 1978, p. 10). Es muy frecuente en Campmany este estilo, sin necesidad de explicitar quiénes quieren seguir "matando toros a pedradas". Una indirecta manera de calificar la acción de quienes barajaban soluciones parlamentarias a los asuntos.

La siguiente referencia al asunto constitucional procede del buen humor de esta columna y de su autor que a veces toma como tema los desenlaces de la vida cotidiana. En aquel mes de octubre nació una hija del entonces líder socialista Felipe González, que todavía no ocupaba cargos de relevancia pública en el país. Con el título "simplemente María" que evocaba una conocida y ridiculizada telenovela emitida en nuestro país arranca otro exordio: “¡Menos mal que ahí están los niños! para retomar el asunto constitucional que está en la mesa: Como a don Felipe González le ha nacido una niña en pleno festival constituyente, le vino la idea de bautizarla con el nombre de Constitución" (Campmany, 1978, p. 7).

Y argumenta: "Seguramente don Felipe González está pensando que esta niña que le ha nacido en el año de gracia de la Constitución, en vez de traer el pan debajo del brazo, puede haberle traído la cartera de primer ministro de su Majestad, porque alguna vez se tendrá que producir el milagro" (Campmany, 1978, p. 7). Concluye la columna con la misma expresión: "Menos mal que ahí están los niños" como recurso retórico habitual en sus escritos para seguir el hilo conductor y rematar como empezó (Campmany, 1978, p. 7).

El entonces presidente Suárez se dirigió en aquellas fechas al Congreso de la UCD y además de asegurar las libertades democráticas, prometió una solución de los problemas regionales que tanto obsesionaban a los españoles del momento, con la explosión potencial de las autonomías. Campmany tituló su columna "Filosofía de la elegancia" (Campmany, 1978, p. 8) y comenzó así: "Pues, no, no habrá sido un discurso de la filosofía de la elocuencia; pero ha sido un discurso para la filosofía de la elegancia" (Campmany, 1978, p. 8). Acude el autor al retruécano, la versión literaria de los acontecimientos sociales y un punto de ironía en su descripción de lo 
que aconteció:

Allí estaba toda la clase política, sector renovado; unos servicios del orden que apenas si hacían falta porque todos éramos gentes de orden; las azafatas de buena familia; la nube de fotógrafos; los cámaras de Gustavo Pérez Puig escaqueados con estrategia de buen director de escena; los policías de paisano; periodistas a manta de Dios... (Campmany, 1978, p. 8)

Con este argumento, respetuoso pero mordaz ofrecía su propio punto de vista y anticipaba una opinión: "Don Adolfo ha dicho que como lo habían hecho presidente del partido (que tampoco eso es una variante en la quiniela) iba a hablar exclusivamente como presidente del partido. Pero después ha hablado también un poco como presidente del Gobierno. Aunque a mí me ha hecho la impresión de que hablaba más que nada como Premio Nobel de la Paz" (Campmany, 1978, p. 8). Si, en cierto modo, parece mofarse de la figura de presidente concluye su escrito con una demostración de su prosa y su prácticamente ilimitado léxico: "Señores políticos de la oposición, están ustedes ante un político indescomponible, incombustible, incarburante, inexpugnable e invulnerable" (Campmany, 1978, p. 8).

Durante la preparación y desarrollo del texto constitucional se habían afianzado dos grandes partidos, la Unión de Centro Democrático (UCD) y el Partido Socialista (PSOE); otros dos partidos menores, Alianza Popular y el Partido Comunista; y varios partidos regionales, entre los que destacaron los representantes del nacionalismo vasco y catalán. Por esta razón, poco después, volvió a aludir a la Constitución con un título humorístico que suavizaba la gravedad del asunto: "Las cuatro esquinas". Y emplea un arranque contundente para centrar el problema: "A medias palabras, el presidente Suárez parece haber querido dar a entender que no habrá elecciones generales inmediatamente después de ser aprobada la Constitución por referéndum" (Campmany, 1978, p. 9).

Inmediatamente ofrece una exposición de motivos que justifican el título: "Como en el juego de las cuatro esquinas, el presidente Suárez puede acudir a cuatro grupos parlamentarios a pedir la lumbre de los votos para cocer ese gobierno" (Campmany, 1978, p. 9). Y con cierto coloquialismo introduce el argumento, que expone a continuación: "En ocasiones en que se avecinaba en el Congreso una votación azarosa, ya se cedió, sin posible recuperación, el término "nacionalidades" para su inscripción en el texto constitucional. (...) Para mantener la mayoría parlamentaria que el gobierno precisa ¿qué otras concesiones habría que hacer?" (Campmany, 1978, p. 9), con una expresiva apelación al lector. Y cierra con fina ironía “A veces la matemática democrática es una asignatura endemoniada" (Campmany, 1978, p. 9).

La última columna de octubre llevó por título "A callar se ha dicho" dedicado a un penoso asunto como era el silencio sobre el terrorismo en el Congreso de los diputados, un tema que, por lo delicado, parecía no querer abordarse claramente. Y comienza Campmany con un expresivo refrán: "Nuestro gozo en un pozo" (Campmany, 1978) para añadir con su inevitable ironía: "El Congreso puede hablar de la planificación familiar, o del plan energético; pero de los muertos, no" (Campmany, 1978). Y con una argumentación impecable expuso: "Una nueva ocasión para que los diputados, los parlamentarios _parlamento viene de parlar, creo yo_ hablen de lo que se habla en la calle, de lo que habla el pueblo, de lo que 
inquieta a la hermosa gente que ya en el proyecto de Constitución es pueblo soberano" (Campmany, 1978). Su conclusión, como de costumbre vuelve al título que le dio pie: "Por ahora estamos en la fase de "a callar se ha dicho", del Parlamento para hablar del tiempo, de la píldora y de los suspensos de los niños" (Campmany, 1978).

Durante este mes de octubre los artículos que firmaba Campmany se publicaron en las páginas 8 y 9, y sin embargo a partir de noviembre las "Escenas políticas" comienzan a tener ubicación fija y preferente en la página 3. Posiblemente el diario era consciente del interés que despertaron estos artículos.

\subsubsection{La cuestión del terrorismo desestabilizador}

El asunto fue creciendo en dimensiones en la calle y pronto comenzaron a oírse en la palestra pública voces a favor y en contra del texto que se estaba preparando. Los periódicos realizaban numerosos augurios sobre la reacción de los españoles. Los nacionalistas vascos empezaron a recomendar la abstención como respuesta, en la votación del texto constitucional. Campmany dedicó una expresiva columna encabezada con una castiza expresión "A beneficio de inventario" en la que explicaba la cuestión en estos términos: “Tengo para mí que la prédica abstencionista de los nacionalistas vascos ante la Constitución va a hacer caer en las urnas del referéndum un montón de síes en el resto del país" (Campmany, 1977,p. 3). Y que argumentó, líneas más adelante: “Porque ¡claro es que hay que respetar las peculiaridades! Y la Constitución las respeta, las respeta hasta el punto de que algunos creen ver el peligro de la desintegración de España" (Campmany, 1977,p. 3). El autor remata rompiendo una lanza a favor del texto: "La Constitución es una tabla de derechos y obligaciones. Hay que aceptarla íntegra. No se puede recibir como una herencia ajena, a beneficio de inventario" (Campmany, 1977,p. 3).

A finales de noviembre, ante la inminencia de la votación, se advierte que vuelve a posicionarse acerca de la Constitución. Los últimos días fue objeto prácticamente diario de sus columnas.

La persistente acción terrorista que estaba desestabilizando el sistema, le inspiró el título, fuerte y tal vez excesivo, "Jazmines y Parabellum". Contextualizaba así el motivo de su trama: “Las primeras páginas de los periódicos tienen un protagonista tenaz y repetido: la muerte y la violencia” (Campmany, 1978, p. 3). Y exponía su argumento con contundencia otra vez: “La imperturbabilidad del gobierno y la actitud confusa y equívoca de los partidos políticos, más preocupados por la exquisitez jurídica y reglamentaria de los cuerpos policiales que del desarme efectivo del terrorismo, están contribuyendo quizás a llenar de sangre la senda constitucional" (Campmany, 1978, p. 3). También en esta ocasión retoma retóricamente el título que le inspiró: “No se puede enviar jazmines a sofocar las parabellum" (Campmany, 1978, p. 3).

Al día siguiente, volvió a abordar la cuestión constitucional. En esta ocasión con el título "La tournée de Dios" que comienza rotundamente: "La Constitución es atea. La Constitución ha expulsado a Dios de sus artículos. La Constitución es abortista" (Campmany, 1977, p. 3). El tono airado con que parece dirigirse al lector parece motivado por una tendencia típicamente española que expone así: “Aquí en cuanto 
se habla de política y de gobierno, acabamos por hablar_D. Francisco de Quevedo aparte_de la política de dios y el gobierno de Cristo" (Campmany, 1977, p. 3). Y sostiene con su rotundidad habitual "Es inútil y ocioso que pretendamos que venga Dios a decirnos lo que debemos votar en el referéndum de la Constitución. Dios no da mítines políticos sino que habla a la conciencia de cada uno, y es cada uno quien debe buscar la verdad dentro de su conciencia" (Campmany, 1977, p. 3). Como de costumbre remata volviendo a su inicio: "La tournée de Dios sólo se produce en la divertida imaginación novelesca de Jardiel Poncela" (Campmany, 1977, p. 3).

Por tercera vez en la misma semana, el sábado 25 de noviembre escribió sobre el asunto. Con el título "Carambola a tres bandas" ataca la actitud el PSOE ante los posicionamientos del País Vasco. Inicia el texto de una manera campechana y coloquial "Si, ya sé. Hay que contar con la ganga" (Campmany, 1978, p. 3). Y subraya en seguida con claridad: "Hay veces en que los políticos juegan a varios paños, en el intento de ampliar, por el lado derecho y por el lado izquierdo, su base electoral" (Campmany, 1978, p. 3). Y afina aún más su argumentación: "Hay casos en los que uno, pobre y soberano elector, empieza a pensar que hay políticos, o partidos, que además de buscar nuestro voto nos están tomando la cabellera" (Campmany, 1978, p. 3). Para rematar, como suele, con un retorno al comienzo, típica figura literaria de sus escritos: "Desde su esquina de espectador, el modesto cronista, pobre y soberano elector, se queda un rato boquiabierto, absorto, patidifuso y turulato contemplando cómo el Partido Socialista acaba de hacer esa difícil y admirable carambola a tres bandas" (Campmany, 1978, p. 3).

Nuevamente el miércoles, 29 de noviembre, retoma la trama con el título "Vista a la derecha" que abre un artículo dedicado al desequilibrio de la política española, en ese momento y casi de manera habitual en este país. Comienza con el siguiente encabezamiento: "Nos balanceamos históricamente sobre la cuerda floja, en piruetas, no ya circenses, sino patéticas" (Campmany, 1978, p. 3). Para la descripción de la situación de estancamiento a la que se refiere hace esta exposición: "Si en este país la izquierda y la derecha hubiesen tirado del carro con potencia igual o con esfuerzos semejantes, el carro habría avanzado, con algún que otro bamboleo pero sin salirse del camino" (Campmany, 1978, p. 3). Y argumenta que: “Lo mejor que podría pasarle a España en estos momentos es que, casi por primera vez e nuestra historia, tuviésemos una izquierda moderada, una derecha progresista y un centro liberal. (...) La política como la tierra es redonda. Y el poder cuando se quiere llevar solo, aplasta" (Campmany, 1978, p. 3). Para rematar líricamente con estas palabras: "El balanceo de la democracia no es el de la cuerda floja. Es el de la hamaca. Ese lugar donde los españoles casi nunca hemos podido echarnos, al aire libre, una siestecita política" (Campmany, 1978, p. 3). Sin embargo, los españoles parecieron ponerse básicamente de acuerdo para construir una carta fundamental que afianzara la Corona y alejara el fantasma de la guerra civil.

\subsubsection{El arrollador sí a la Constitución}

En el mes de diciembre se difundió una carta pastoral de monseñor Marcelo González Martín, presidente entonces de la Conferencia Episcopal española, a propósito del texto constitucional. Ello dio pie a una columna que se tituló " $\mathrm{La}$ 
guerra santa" y que su autor empieza con estas expresiva y coloquial expresión: “¡Válgame Dios y buena la ha armado D. Marcelo!" (Campmany, 1978, p. 3) lo que a renglón seguido explica así: “Al final, de cada contienda patriótica o de cada disputa política terminamos por hacer una guerra santa" (Campmany, 1978, p. 3). Y para argumentarlo aduce:

Cuando los españoles intentamos la humana y fascinante aventura de querer pensar por nuestra cuenta llega alguien con la "Summa Teológica" en la mano para aplastar a Kant y cuando queremos resolver nuestros problemas de convivencia política y ciudadana, siempre hay anillos pastorales que bendicen un programa, que nos ponen a Dios por delante de los reales decretos o que sepultan las opiniones, y aun los acuerdos, bajo una lluvia de anatemas y excomuniones. (Campmany, 1978, p. 3)

Y sugiere, conciliador, en el cierre de su columna: "Ya que no hemos hecho de esta Constitución una implacable querella política, no hagamos de ella una nueva guerra santa."

Al día siguiente, el Rey pronunció un discurso en el que como era lógico por la inmediatez de las fechas, hizo una referencia a nuestro proceso constitucional que Campmany recoge con el título "Amor americano" Ese lugar donde los españoles casi nunca hemos podido echarnos, al aire libre, una siestecita política". El asunto lo plantea así: "Parece que lleváramos cinco siglos tendiéndonos las manos España y América" (Campmany, 1978, p. 3), y lo expone con estas frases: “El rey ha llevado a América la imagen y el ejemplo de esta España que está a punto de darse la Constitución más democrática de toda su historia" (Campmany, 1978, p. 3). Toda su argumentación se centra en defender o en presentar favorablemente la figura del Rey. "Y aquí el rey ha dado de nuevo el ejemplo de la concordia y la reconciliación estas sustancias espirituales sin las cuales todo lo que estamos edificando se vendría pronto abajo como un ilusorio castillo de arena" (Campmany, 1978, p. 3). La columna se cierra con una toma de posición aún más clara: "El rey "primer español obligado a cumplir con su deber" como él mismo quiso proclamar desde el primer día que habló como rey de todos los españoles, ha empezado a realizar su misión" (Campmany, 1978, p. 3).

La víspera de la votación la columna se tituló "Zarabanda en sí menor" en alusión humorística a las distintas posiciones ante el referéndum constitucional. Comienza el autor con este preámbulo: "La Constitución que es como el calvario de nuestra democracia tiene también sus tres Marías" y con agudeza señala: "La dialéctica del Referéndum se desenvuelve, como ven, entre melindres y un mírame-y-no-me toques de invitación al vals" (Campmany, 1978, p. 3). Con lógica irreprochable expone su argumento: "Entre unos y otros han armado en contra del "no" una zarabanda de síes que no va a terminar como el rosario de la aurora porque cada españolito va a demostrar seguramente que tiene más serenidad que quienes deberían darle ejemplo de serenidad" (Campmany, 1978, p. 3). Y por descontado para rematar el artículo vuelve al origen de su admonición: "Estamos subiendo el calvario de la democracia que se llama Constitución. Con toda esta zarabanda de los síes y el contrapunto de los noes en las vallas, en los carteles, en los mítines y en la televisión" (Campmany, 1978, p. 3). Aquel día destacó la alocución del presidente 
Suárez por TV alentando al país: "Esta Constitución rompe el mito de la España diferente, ingobernable y anárquica"; y una referencia al terrorismo que "ha intentado frenar con sus actuaciones cada paso hacia mayores cotas de libertad"(Campmany, 1978, p. 3).

El mismo día de las votaciones prosigue con su retórica de corte hispano titulando su columna "El cáliz de la investidura" para referirse a la inevitable investidura como tal del presidente del gobierno, Adolfo Suárez. El asunto lo introdujo con las siguientes palabras: "Supongo que todo ese zafarrancho de la investidura de don Adolfo no tiene nada que ver con la vieja querella de las investiduras ¡Pues bueno está ahora el patio para que nos metiéramos en ese berenjenal!" (Campmany, 1978, p. 3). Para contextualizar la inevitabilidad de los acontecimientos y justificar el título expuso: "El cáliz está ahí en la disposición adicional octava del texto constitucional que esta mañana estamos votando "si quieres seguir en La Moncloa, a pasar por el aro de la investidura" (Campmany, 1978, p. 3) y profundiza su argumentación: "Nos hemos pasado casi dos años hablando de la Constitución by ahora nos esperan casi dos años hablando de la investidura (...) ¿no queríamos urnas? ¡Pues tomar urnas!" (Campmany, 1978, p. 3). El cierre del artículo vuelve a ser un derroche de léxico y de humor, anticipador de una libertad aun no suficientemente asentada: "Y a don Adolfo que lo invistan, que lo vistan, que lo desvistan o que lo travistan, pero que gobierne de una vez" (Campmany, 1978, p. 3), con el que además interpela al mismo presidente para que deje sentir su actuación de una manera más expresa.

La prensa celebró el "Arrollador sí a la Constitución" y con tal motivo se publicaron suplementos especiales sobre el Referéndum y el desarrollo del mismo en distintos puntos de España. La columna "Escenas políticas" trató de comentar unos resultados apenas esbozados. El título "Radiografía del paciente" estaba ya cargado de sorna. Y el comienzo contundente y lenguaraz: "A la fauna electoral ibérica se nos va a someter a observación, a vivisección, a reconocimiento y a biopsia" (Campmany, 1978, p. 3). Pero la observación de los resultados sólo permite al autor hacer este comentario. "Una cosa, al menos, está clara; que los españoles del sí han aplastado electoralmente a los españoles del no" (Campmany, 1978, p. 3). Pero explicó con más detenimiento y con su buena dosis de ironía que:

Uno de los entretenimientos más divertidos de la democracia es este de los juegos malabares que todos hacen con los resultados electorales (...) en el trance electoral de las democracias las matemáticas dejan de ser una ciencia exacta para convertirse enana ciencia mágica y oculta, donde los números cuentan su vida de manera diferente, con una fantástica desfachatez. (Campmany, 1978, p. 3)

Y para concluir, echa mano el autor del refranero: "Y luego ¡qué cosas han dicho de la Constitución! Nunca llueve a gusto de todos, pero en una Constitución para que dure tiene que llover a gusto de nadie" (Campmany, 1978, p. 3).

Y al día siguiente, rompió una lanza a favor del presidente Suárez con la columna titulada "Gracias, señor Presidente" que comenzaba con guasa "Me levanto hoy para agradecer, aunque sea con decorosa incontinencia..." (Campmany, 1978, p. 3) para agradecer el trabajo realizado en el curso de la reforma política del país. "Don Adolfo Suárez tuvo que hacer una Reforma política que requería una combinación muy 
dosificada de prudencia y de audacia" (Campmany, 1978, p. 3). Y aseguraba "Creo que somos pocos los que -sin tener que llevar el agua a nuestro molino ni arrimar el ascua a nuestra sardina- hemos reconocido algo que es de justicia" (Campmany, 1978 , p. 3). Para concluir "Creo que hoy sería justo decir gracias presidente, aunque fuese una frase de despedida" (Campmany, 1978, p. 3).

En la siguiente semana, somete a su agudeza la situación del país con tan repetidas convocatorias a votar. La columna ya se titula "Votando espero" que cualquiera era capaz de asociar al conocido tango y plagiando con humor el texto comienza así "Votar es un placer genial, sensual" (Campmany, 1978, p. 2) y lo contextualiza con su natural claridad "Ya hemos votado tres veces. Pero que no se lleven las urnas demasiado lejos" (Campmany, 1978, p. 2). En su argumento, como en tantas ocasiones, una peculiaridad de la idiosincrasia española "En este país se vota con más gana cuando se vota contra alguno. (...) Pero si se va a votar contra nadie, ya la cosa no tiene gracia" (Campmany, 1978, p. 2). Y para concluir de nuevo en referencia al título: "Y las urnas que no se las lleven demasiado lejos. En la democracia, ya se sabe: votando espero" (Campmany, 1978, p. 2).

Seis días después de aprobada la Constitución el Rey recibió a la ejecutiva del PSOE que acataba de esta forma la Monarquía Constitucional. Y el país se convirtió en un hervidero de rumores acerca del derrotero que iba a seguirse. La columna correspondiente se titulaba "Que nada se sabe" y era una directa invectiva contra los rumores que se extendían por toda la nación como forma de comunicación. Comienza con este anuncio: “Los políticos, los periodistas y los correveidiles andamos desaforados dándonos noticias que no lo son los unos a los otros" (Campmany, 1978, p. 3). Para enseguida poner en situación al lector: "Una de las primeras cosas que hemos aprendido en la democracia es la picardía del mentidero, la técnica del lobo-sonda, el lugar del farol, el "hacer que no vuelvo y volver" (Campmany, 1978, p. 3). Y alude a su propia experiencia para defender el argumento de que no hay nada seguro "Bueno, pero ¿qué es lo que va a pasar? ¿Va a haber reajuste de gobierno, investidura o elecciones generales? $Y$ hay un señor que te contesta muy seguro de sí mismo, las tres cosas. Y otro que no haga caso" (Campmany, 1978, p. 3). Esta columna concluye con un dardo final que resultó profético en una parte: “Que ya me enteraré de todo por don Ricardo de la Cierva o cuando lea las memorias de don Adolfo Suárez" (Campmany, 1978, p. 3).

Este mes que fue pródigo en columnas dedicadas al asunto constitucional por razones obvias, se publicó otra que ostentaba el título "El retablo de las maravillas" para referirse a las contradicciones de este país. Comienza afirmando con rotundidad “Definitivamente vivimos en un país mágico. Aquí la magia triunfa siempre sobre la lógica" (Campmany, 1978, p. 4). La narración del acontecimiento que le mueve a escribir es esta: "Acabamos de aprobar la Constitución donde se dice que esto es una monarquía parlamentaria y ahora, cuando tenemos que darle más vida al Parlamento, llega un diputado y dice jesto es un cadáver!" (Campmany, 1978, p. 4). Pero describe dramáticamente en su argumentación la penosa situación por la que atravesaba España, con palabras así:

D. Marcelino no dice una palabra sobre el ametrallamiento de nuestros pesqueros, votamos contra Chile en la ONU; no conseguimos abrir ni un 
resquicio de Europa. Y no se firman los pactos. Y no se arregla la economía. Y la administración pública no funciona. Y todo está parado, aparte de un millón de españoles. El teatro agoniza. El cine está muerto. En este momento no hay en rodaje una sola película española. Las gentes no salen de noche. Los ministros no saben si van a seguir siendo ministros." Un retrato que para atenuar el efecto, cierra con esta reflexión: "Vivimos en un país mágico. Esto, señores, es el retablo de las maravillas. (Campmany, 1978, p. 4)

Parte del buen uso que Campmany supo hacer del humor y la ironía se manifiestan en los dos últimos artículos que se corresponden con las columnas de "Escenas Políticas" de los días 29 y 30 de diciembre del año de la Constitución democrática. Con el título "El asno de Balaam" hizo una fina crítica a la actitud indecisa del gobierno y más en particular del presidente Suárez. Comienza con este aserto: "Yo no sé por qué los burros tienen esa fama de tontos ni por qué a los tontos se les castiga con orejas de burro" (Campmany, 1978, p. 3) que ya predispone la sonrisa en el lector. Y la crítica comienza ya desde la exposición de hechos "Yo me imagino al presidente Suárez, en estos momentos, encaramado, con perdón sobre la burra de Balaam, y sin decidirse todavía a tomar el camino de la investidura o el de las elecciones" (Campmany, 1978, p. 3). Mucho más fuerte en el argumento que sostiene "Pero también en el camino de las elecciones pueden aparecer sorpresas y sinsabores. La conformación actual del Congreso aparece un tanto ficticia en relación con el panorama político de la sociedad española. (...) La solución a la charada constitucional podemos tenerla desde hoy en cualquier momento" (Campmany, 1978, p. 3). Y no deja de echar un capote, o intentar leantar el ánimo cuando culmina su texto con "Para mi es seguro que el asnillo de Balaam ya haya tomado un camino. Lo que no se sabe es a dónde nos llevará" (Campmany, 1978, p. 3).

Ratificada la Constitución se entró en una fase, siempre bajo la presidencia de Suárez, dominada cada vez más por el peso de graves problemas reales: el paro, el terrorismo, frente al que la acción del Estado parecía cada vez más ineficaz, la inhibición de los empresarios, la amenaza de la lucha de clases, la política exterior vacilante y pretenciosa pese a la profesionalidad de sus ejecutivos, la crisis económica galopante y la desorientación cultural de la sociedad y del Estado, que desembocarían en un recrudecimiento de los extremismos y en un general desencanto del pueblo español de su democracia naciente.

La historia política de España en el año 1979 estaría dominada principalmente por tres procesos: las elecciones generales y municipales, la crisis del PSOE, y el planteamiento del problema autonómico en fase virulenta. Y así se avanza en la última columna de "Escenas Políticas" de aquel año 1978 que tuvo por título "iQue traigan las urnas!". El autor introduce con suavidad el asunto "A veces, desgraciadamente sólo a veces, las cosas acaban siendo como tienen que ser" para destacar las cualidades en su opinión del proceso vivido "El proceso de cambio político que discurre entre el 20 de noviembre de 1975 al 29 de diciembre de 1978 es ejemplar en su claridad y en su proceso pacífico" (Campmany, 1978, p. 3). Pero también alude ya a la fatiga del pueblo antes las reiteradas convocatorias: "Las elecciones generales se presentaban a mi juicio como algo no ya conveniente sino inevitable. Y eso a pesar del cansancio electoral de los ciudadanos y la excesiva dosis 
de votaciones que nos está administrando una democracia recién estrenada" (Campmany, 1978, p. 3). Y cierra la columna con la apelación festiva: "Por lo tanto, que traigan de nuevo las urnas" (Campmany, 1978, p. 3).

Podría cerrarse este epígrafe con términos del propio autor: "la sátira es con frecuencia un recurso de quien no puede cambiar la situación y se ríe de ella" (Cantavella 2011, p. 82) que muy bien definen el tono con el que escribió estos artículos.

\section{CONCLUSIONES}

El análisis descriptivo realizado sobre el tratamiento de la Constitución española de 1978, en los meses inmediatos a su aprobación, a través de la columna "Escenas Políticas" permite apuntar al menos las siguientes consideraciones:

1. Jaime Campmany con su enorme facilidad para tratar asuntos de actualidad, así como para dirigir sus dardos contra sus enemigos políticos, abordó en su columna política los asuntos públicos de la nación, en concreto la aprobación del texto constitucional, desde una posición conservadora y con un gran sentido del humor.

2. Esta derivación hacia el humor, con recursos a la ironía y la sátira en múltiples ocasiones, fue una manera de introducir asuntos que no hubieran tenido cabida de otro modo. Posiblemente porque no tuvo más remedio que emplear la sátira, dada la aparente incompetencia de la nación para promover cambios imprescindibles. En sus columnas "Escenas políticas" tomó abiertamente partido en defensa de las ideas conservadoras.

3. Los artículos de estas columnas evidencian una gran calidad literaria, posiblemente como resultado del ejercicio profesional de largos años y de su arte para captar la benevolencia del público. Es habitual en sus textos el recurso a figuras literarias como la anáfora, que evidencian también la claridad con que sostenía sus planteamientos a lo largo de un hilo conductor.

4. Más que razonamientos argumentados, lo que utilizaba en sus ataques directos a sus adversarios, fueron elementos humorísticos de refuerzo como: poner de relieve los errores ajenos, descubrir vicios, ridiculizar comportamientos y, sobre todo, la caricaturización de los personajes.

5. Esas columnas evidencian la riqueza léxica y el dominio del vocabulario de que disponía. Utiliza numerosos términos, procedentes tanto del español culto como del coloquial, de jergas y de dialectos. Con facilidad acumula sinónimos, o adjetivos, o enumeraciones de una manera retórica.

6. Sus textos permiten advertir que había leído y dominaba a los clásicos y como tal escribía con una prosa ágil, con un carácter marcadamente literario (pese a tratarse de cuestiones políticas), con clara expresión y ayudado de imágenes 
y metáforas. Muestra su capacidad intelectual con un lenguaje repleto de cultismos.

\section{REFERENCIAS}

Aguilar, M. A. (1982). El vértigo de la prensa. Madrid: Ed. Mezquita.

Altschull, H. (1984). Agents of Power: The Role of the News Media in Human Affairs. Longman. White Plains.

Astorga, A. (2005, Mayo, 10). Jaime Campmany: A mi edad me lo puedo permitir todo, $A b c$, pp.54-55.

Bajtin, M. (2002). La cultura popular en la edad media y en el renacimiento. Madrid: Alianza.

Barreiro Fernández, X. R. (1979). Historia de Galicia. A Coruña: Ed. A.N.P.G.

Cantavella, J. (2012). La columna en verso: recuerdo y presencia de poetas y versificadores. Doxa comunicación; $13 ; 67-88$.

Campmany, J. (1997) Doy mi palabra. Mis 100 mejores artículos. Madrid: Espasa Calpe.

Lasswell, H. (1948). The Structure and Function of Communication in Society, En LBrison, The Communication of Ideas. Nueva York: Harper and Brothers.

Llera, J. A. (2003). El humor verbal y visual de La Codorniz. Madrid: CSIC.

Lynch, O. (2002). Humorous Communication: Finding a Place for Humor in Communication Research. Communication Theory. 12/4.

McQuail, D. (1998). La acción de los medios. Los medios de comunicación y el interés público. Buenos Aires: Amorrortu editores.

Mendelsohn, H. (1966). Mass Entertainment. New Haven: College and University Press.

Morales Castillo, F. (1999). El recurso del humor en el periodismo de opinión. Piura: Universidad de Piura.

Sinova, J. (1989). La difícil evolución de las empresas no estatales. In J. Timoteo Alvarez y otros. Historia de los Medios de Comunicación en España (1900-1990). Barcelona: Editorial Ariel.

Wright, Ch. (1959). Functional Analisys and Mass Communication. Public Opinion Quarterly, 24.

Fuentes hemerográficas

La Voz de Galicia, 1975-1978

$A B C, 1978$

\section{AUTORAS}

\section{Aurora García González}

Doctora en Comunicación Pública y, en la actualidad, Profesora Titular de Periodismo con acreditación para el Cuerpo de Catedráticos, en la Facultad de Ciencias Sociales y de la Comunicación de la Universidad de Vigo. Es Directora de la Sección Departamental de Comunicación e IP del grupo de Investigación CS1 (ICOM) de la misma Universidad. Autora de numerosos publicaciones y artículos científicos. Imparte la materia "Opinión Pública", en el Grado de Publicidad y el curso "Modelos de radio: innovaciones y usos sociales" en el Master en Investigación 
en Comunicación.

$\underline{\text { http:/ / 0000-0003-3757-9047 }}$

\section{Sarai Lagos Area:}

Doctora en Investigación en Comunicación por la Universidad de Vigo. Miembro del Grupo de investigación CS1 (ICOM) de la misma Universidad. Graduada en Publicidad y RR.PP. por la Universidad de Vigo. Miembro del Grupo de investigación que desarrolló el Proyecto sobre Valores en la Publicidad que dio origen a la publicación "La educación en valores a través de la publicidad. Las campañas publicitarias de la ONCE en la radio" en Correspondencias EAnálisis (2015). Redactora y community manager de Publicaciones Andamio (Barcelona).

\section{$\mathbf{M}^{\mathrm{a}}$ Lourdes Román Portas}

Doctora en Investigación en Comunicación por la Universidad de Vigo. Miembro del Grupo de investigación CS1 (ICOM) de la misma Universidad. Licenciada en Filología Hispánica y Gallego-portuguesa, ambas por la Universidad de Santiago. Miembro del Grupo de investigación que desarrolló el Proyecto Estudios sobre el reflejo de la cultura y la sociedad gallega en el cine de ficción hecho en Galicia y sobre Galicia, financiado por la Secretaría Xeral para las relaciones con los medios informativos de la Xunta de Galicia.

Http:/ / 0000-000313669961 